Genome Insight Plant Genetics

\title{
The first complete plastome of Mimusops coriacea (A. DC.) Miq. (Sapotaceae)
}

\author{
Rafaela Jorge Trad ${ }^{1,2}$ (D), Saura Rodrigues da Silva ${ }^{3}$ (D) and Maria do Carmo Estanislau do Amaral ${ }^{1}$ (D) \\ ${ }^{1}$ Universidade Estadual de Campinas (UNICAMP), Instituto de Biologia, Departamento de Biologia \\ Vegetal, Campinas, SP, Brazil. \\ ${ }^{2}$ Universidade Federal de Minas Gerais (UFMG), Instituto de Ciências Biológicas (ICB), Laboratório \\ de Macroecologia, Belo Horizonte, MG, Brazil. \\ ${ }^{3}$ Universidade Estadual Paulista (UNESP), Faculdade de Ciências Agrárias e Veterinárias, Departamento \\ de Biotecnologia Agropecuária e Ambiental, Jaboticabal, SP, Brasil.
}

\begin{abstract}
Mimusops coriacea (A. DC.) Miq. (Sapotoideae, Sapotaceae, Ericales) is native to Madagascar and the Comoro Islands. This species is cultivated in many countries around the world and grows on sand in coastal vegetation. Here we sequenced, assembled, and annotated the first complete chloroplast genome of $M$. coriacea. The newly assembled chloroplast was analyzed with other available chloroplasts of Sapotaceae. Our results found a general conserved structure. The complete chloroplast genome has 159,689 bp, including 133 genes distributed in four regions: a large single-copy region of $88,887 \mathrm{bp}$, a small single-copy region of $18,618 \mathrm{bp}$, and two inverted repeats of 26,092 bp each. Our maximum likelihood phylogenetic tree was generated with 80 protein-coding genes and recovered a monophyletic Sapotaceae sister to a clade formed by Ebenaceae + Primulaceae. In our analysis, Mimusops coriacea clustered with the other eight species of Sapotaceae included in the study.
\end{abstract}

Keywords: Ericales, complete chloroplast genome, Sapotoideae.

Received: June 14, 2021; Accepted: November 28, 2021.

The family Sapotaceae (Ericales) is represented by 53 genera and between 1,100 and 1,275 species (Stevens, 2001, onwards). In Brazil, there are 13 genera, including about 240 species, which grow mostly in the Amazon and the Atlantic Forest (Alves-Araújo et al., 2020). Although the genus Mimusops L. has 41 species only two occur in Brazil, both cultivated: Mimusops coriacea (A. DC.) Miq. and M. elengi L. (Pennington, 1990; Alves-Araújo, 2020). Mimusops coriacea is native only to Madagascar and to the Comoro Islands, where it grows on the sand in coastal forests and its edible fruits can be found in local markets (Gautier et al., 2012). This species has also been widely cultivated in the tropics. The flowers of $M$. coriacea are similar to those of other species in the genus and are among the most complex in the family. They have two whorls of sepals, corolla lobes with lateral appendages, and staminodes (Pennington, 1990; Gautier et al., 2012). The wood of Mimusops coriacea is used for construction, its branches and branchlets are fermented to prepare a beverage in the Antilles, and the fruits can be eaten; it is also used in traditional medicine in Ecuador (Bustamante et al., 2019), and recently its phytochemical and bioactive potential was corroborated (Bustamante et al., 2021). According to Pennington (1990), the identification of genera of Sapotaceae is challenging and depends on a combination of characters, since no character is diagnostic. Quite different treatments were proposed depending on the character chosen (compare Aubreville (1964) and Baehni (1965) as an example). This

Send correspondence to Rafaela Jorge Trad. Universidade Estadual de Campinas (UNICAMP), Instituto de Biologia, Departamento de Biologia Vegetal, CP 6109, 13083-970, Campinas, SP, Brazil. E-mail: rafajt@ hotmail.com situation, added to the absence of a comprehensive treatment for the family in the Neotropics since Flora Brasiliensis (Miquel, 1863), resulted in considerable confusion with illdefined generic limits and genera with numerous synonyms (Pennington, 1990). Thus, the development of tools that allow us to address phylogenetic relationships and clarify generic limits is extremely important for Sapotaceae. To our knowledge, there are published plastomes from only six genera in the family (Jo et al., 2016, Khayi et al., 2020, Liu et al., 2019, Niu et al., 2018, 2020, Tao et al., 2021, Wang et al., 2021). Therefore, we present the first complete plastome for a species of the genus Mimusops.

Leaves from the collection N. Hanazaki n. 33759 deposited in the herbarium at the University of Campinas (UEC) under the voucher number 90949 were used for DNA extraction. The leaves were grinded for 60 seconds in $2 \mathrm{~mL}$ tubes using TissueLyserII (Qiagen, Hilden, Germany - Cat. No. 85300) and the total DNA was extracted using a modified version of the Doyle and Doyle (1987) CTAB protocol. The DNA was purified using the Wizard ${ }^{\circledR}$ SV Gel and PCR Clean-Up System (Promega, Madison, USA - Cat. No. A9282). Whole-genome libraries were prepared by Genohub Inc. facility (Austin, USA) and paired-end reads ( $2 \times 150 \mathrm{bp})$ were sequenced on Illumina NextSeq 500 platform (Illumina Inc., San Diego, USA), resulting in a total of $10,687,184$ reads. The whole chloroplast was de novo assembled using NOVOPlasty v. 3.8.2 (Dierckxsens et al., 2017) using the $r b c \mathrm{~L}$, accession number L01932.2, as seed. Reads were mapped to the chloroplast with Bowtie2 (Langmead and Salzberg, 2012) plugin in Geneious 9 (Kearse et al., 2012) using default parameters to validate the assembly and verify the coverage. A total of 503,543 reads mapped the assembled plastome with mean coverage of 412.8 . 
Automatic annotation was done using GeSeq (Tillich et al., 2017) implemented on the Chlorobox website. Start and stop codons were visually inspected and manually adjusted on Geneious 9 (Kearse et al., 2012), and tRNAs limits were corrected based on ARAGORN (Laslett and Canback, 2004) output. Potential pseudogenes were defined by Blast following Silva et al. (2018). The annotated chloroplast was submitted to GenBank under the accession number MW846242. A circular map was generated with OGDRAW (Lohse et al., 2013). Five plastomes from Sapotaceae had the quadripartite structure annotated, i.e., the large single copy (LSC), the small single copy (SSC), and the two inverted repeats (IR): Madhuca hainanensis Chun \& F.C. How, Manilkara zapota (L.) P. Royen, Pouteria caimito (Ruiz \& Pav.) Radlk., Sideroxylon wightianum Wall. and Synsepalum dulcificum (Schumach. \& Thonn.) Daniell. These five plastomes were aligned with Mimusops coriacea using progressive Mauve algorithm in Mauve Plugin v. 2.3.2 (Darling et al., 2004) in Geneious 9 (Kearse et al., 2012) to check for structural differences such as inversions or rearrangements. The limits between the four main regions of these six plastomes were evaluated with IRscope (Amiryousefi et al., 2018). Forward, palindromic, complementary, and reverse repeats were identified in REPuter (Kurtz et al., 2001); parameters were set as follows: minimal size of $30 \mathrm{bp}$ and Hamming distance of 3. Simple sequence repeats (SSRs) were identified in MISA (Beier et al., 2017; Thiel et al., 2003) with a minimum number of 7, 4, 4, 3, 3, and 3, for mono-, di-, tri-, tetra-, penta-, and hexanucleotide repeats, respectively. To determine the position of Mimusops coriacea within Sapotaceae we selected 16 plastomes from Ericales on the GenBank database: three from Ebenaceae, two from Primulaceae, eight from Sapotaceae, two from Styracaceae, and one from Theaceae. All species information and GenBank accession numbers are presented in Table S1. A total of 80 protein-coding and four rRNA genes were aligned with MAFFT v 7.435 (Katoh and Standley, 2013). A maximum likelihood tree based on the concatenation approach considering different evolutionary models for each locus was generated with IQTREE 2 (Minh et al., 2020).

The general structure and the gene order of the plastome of $M$. coriacea are similar to those of the other five genera of Sapotaceae (Madhuca hainanensis, Manilkara zapota, Pouteria caimito, Sideroxylon wightianum and Synsepalum dulcificum) (Figure 1). The complete plastome has a total length of $159,689 \mathrm{bp}$, including a LSC of $88,887 \mathrm{bp}$, a SSC of $18,618 \mathrm{bp}$, and two IRs each of $26,092 \mathrm{bp}$. The GC content was $36.8 \%$ for the complete chloroplast, $34.6 \%$ for the LSC, $30.2 \%$ for the SSC and $42.9 \%$ for the IRs. The whole plastome and its four main regions have both similar sizes and respective GC content among all analyzed Sapotaceae species (Table 1). Mimusops coriacea plastome contains a total of 133 genes of which 81 are unique protein-coding genes, 30 are tRNA and four are rRNA genes (Figure 2). Seven protein-coding, seven tRNA and four rRNA genes are in the IR duplicated region. No rearrangements were observed in the chloroplast of the analyzed Sapotaceae species as occur in some other families from Ericales. However, rearrangements have been reported in the order, i.e., the $c l p \mathrm{P}$ loss in Actinidiaceae (Wang et al., 2016), the highly reduced and rearranged plastome of non-photosynthetic Ericaceae (Logacheva et al., 2016; Braukmann et al., 2017), a $20 \mathrm{~kb}$ inversion in two genera of Styracaceae (Cai et al., 2021), and the pseudogenization of the pt-accD and transfer to the nucleus in Primula sinensis Sabine ex Lindle (Primulaceae) (Liu et al., 2016).

All the analyzed Sapotaceae plastomes have the junctions between single-copy and repeated regions in the same location as those of a typical angiosperm plastome (Wang et al., 2018). The LSC-IRb limit is flanked by $r p l 22$ and $r p s 19$ on the LSC side and by $r p l 2$ on the IRb side. The IRb-SSC junction has the $y c f 1$-fragment on IRb in Madhuca hanainensis and Mimusops coriace and the $n d h \mathrm{~F}$ on SSC; only in Synsepalum dulcificum the $n d h \mathrm{~F}$ spans the junction. We believe the absence of the $y c f 1$-fragment in other species is just an annotation issue. The $y c f 1$ spans the SSC-IRa junction and the IRa-LSC junction is flanked by $r p l 2$ on IRa side and by $t r n \mathrm{H}$ on LSC in all species but Synsepalum dulcificum which has a tRNA instead of the $\operatorname{trn} \mathrm{H}$ (Figure S1). In Mimusops coriacea chloroplast, 16 genes have one intron each and two genes $(y c f 3$ and $c l p \mathrm{P})$ have two introns each. REPuter (Kurtz et al., 2001) identified 49 long repeats in Mimusops coriacea, being 15 palindromic, 18 forward, eight reverse and eight complementary. For the other five Sapotaceae species included, between 30 repeats

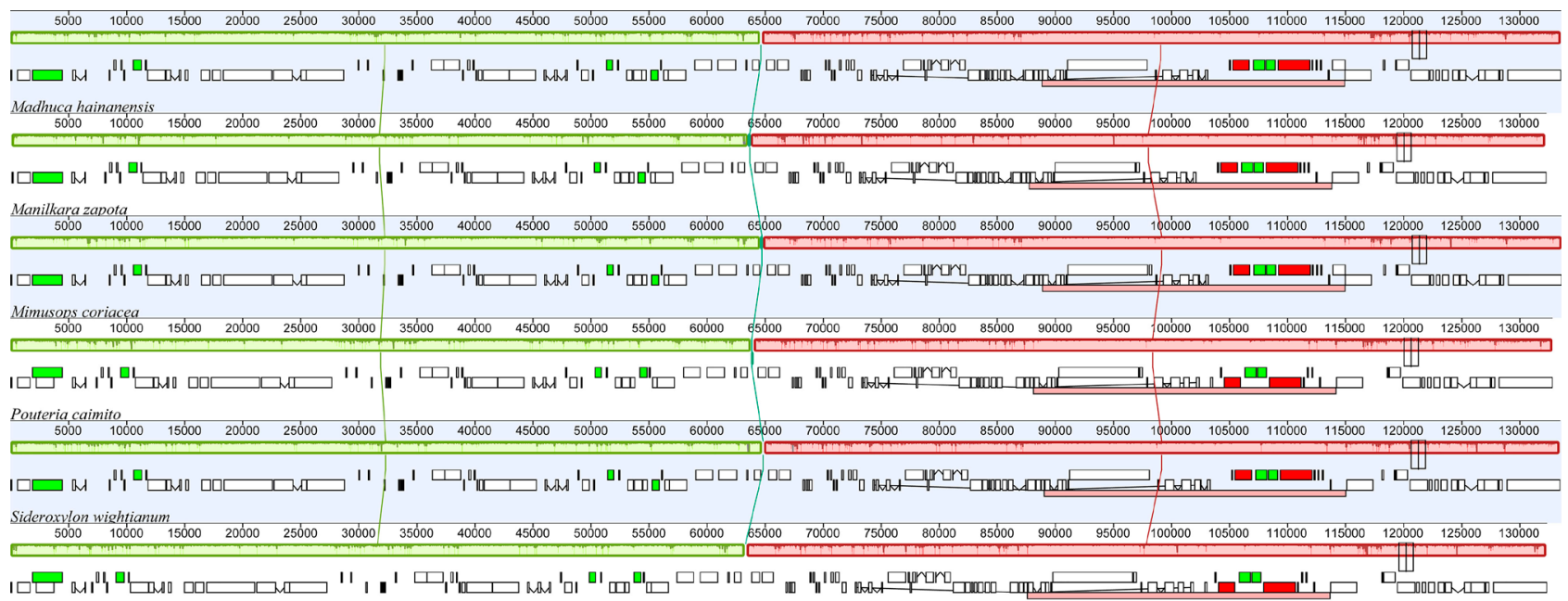
Svnsepalum dulcificum

Figure 1 - Progressive Mauve alignment showing synteny and rearrangements for six Sapotaceae plastomes. Species names are indicated below each respective plastome. 
Table 1 - Comparison of chloroplast genome size and GC content across three different regions (LSC, SSC, and IR) for six Sapotaceae species. LSC large single copy; SSC - small single copy; IR - inverted repeat.

\begin{tabular}{|c|c|c|c|c|c|c|c|c|}
\hline \multirow{2}{*}{ Species } & \multicolumn{2}{|c|}{ LSC } & \multicolumn{2}{|c|}{$\mathrm{SSC}$} & \multicolumn{2}{|c|}{ IR } & \multicolumn{2}{|c|}{ Complete plastome } \\
\hline & $\mathrm{bp}$ & $\% \mathrm{GC}$ & $\mathrm{bp}$ & $\% \mathrm{GC}$ & $\mathrm{bp}$ & $\% \mathrm{GC}$ & $\mathrm{bp}$ & $\% \mathrm{GC}$ \\
\hline Madhuca hainanensis Chun \& F.C. How & 88,846 & 34.6 & 18,598 & 30.1 & 26,093 & 42.9 & 159,630 & 36.8 \\
\hline Manilkara zapota (L.) P.Royen & 87,745 & 34.9 & 18,443 & 30.2 & 26,099 & 42.9 & 158,386 & 37.0 \\
\hline Mimusops coriacea (A. DC.) Miq. & 88,887 & 34.6 & 18,618 & 30.2 & 26,092 & 42.9 & 159,689 & 36.8 \\
\hline Pouteria caimito Radlk. & 88,096 & 34.6 & 18,620 & 30.2 & 26,100 & 42.9 & 158,916 & 36.8 \\
\hline Sideroxylon wightianum Hook. \& Arn. & 89,043 & 34.7 & 18,365 & 30.4 & 26,065 & 42.9 & 159,538 & 36.9 \\
\hline Synsepalum dulcificum (Schumach. \& Thonn.) Daniell & 87,574 & 34.7 & 18,635 & 30.1 & 26,127 & 42.9 & 158,463 & 36.9 \\
\hline
\end{tabular}

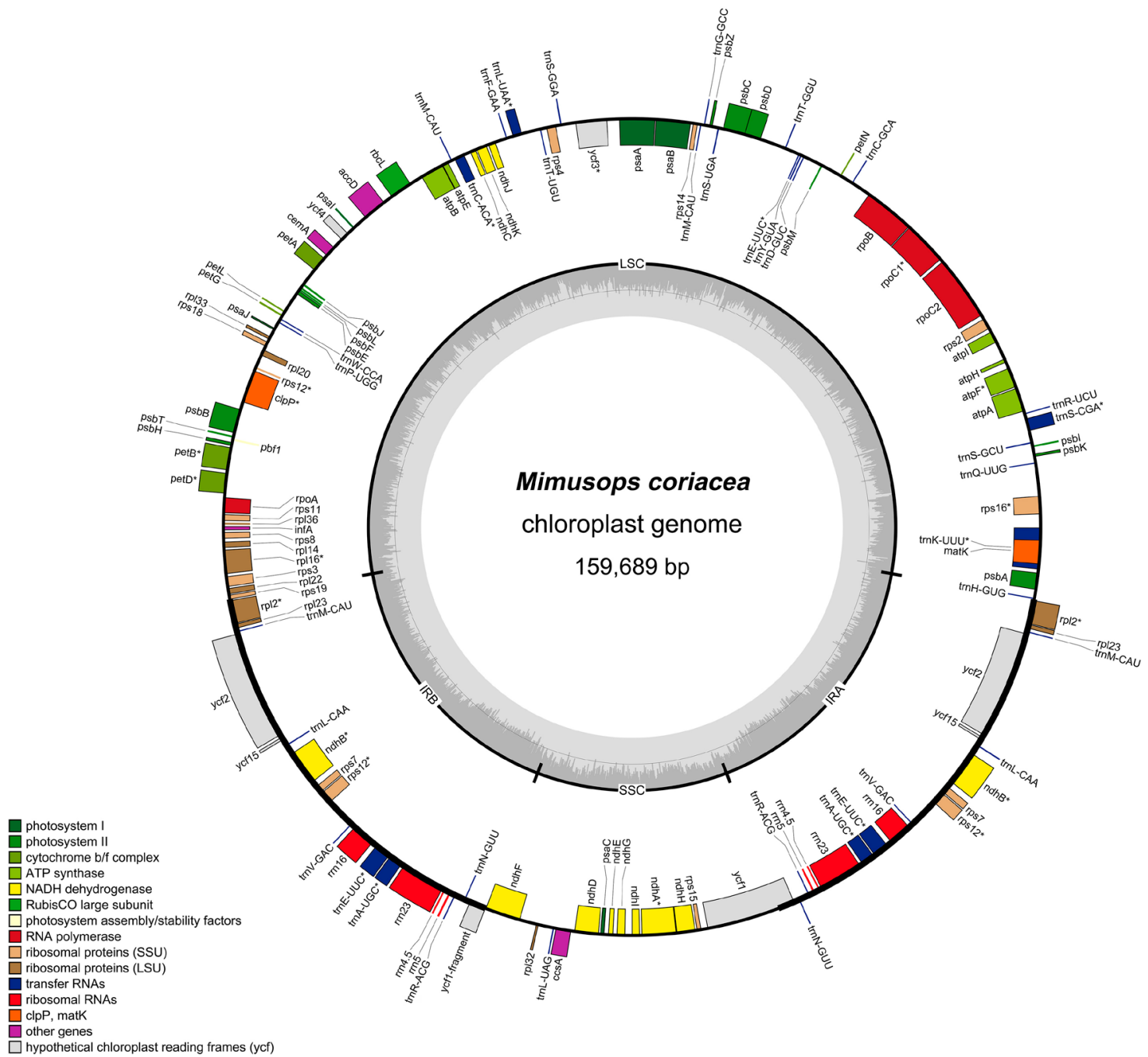

Figure 2 - Circular map of Mimusops coriacea complete chloroplast genome. The genes represented outside the circle are transcribed counterclockwise and those inside the outer circle are transcribed clockwise. Genes are colored according to their functional groups following the legend. The inner gray graphs indicate the GC content across the plastome.

in Synsepalum dulcificum and 50 repeats in both Madhuca hainanensis and Sideroxylon wightianum were found (Table S2). MISA v. 2.1 (Beier et al., 2017; Thiel et al., 2003) identified 344 SSRs throughout Mimusops coriacea plastome. Among these repeats 287 are mono-SSR and 47 are di-SSR, four are tri-SSR, five are tetra-SSR and one is penta-SSR. Similar number of repeats were observed in the other five Sapotaceae species included (Table S2).

Relationships within Ericales are not fully understood (Stevens, 2001, onwards). In our maximum likelihood tree,
Sapotaceae was recovered as monophyletic and sister to the clade Ebenaceae + Primulaceae, which agrees with Rose et al. (2018). On the other hand, Larson et al. (2020) recovered Sapotaceae as sister to Ebenaceae, and Primulaceae not close to that clade. In Sapotaceae, Mimusops coriacea clustered with the other eight species from the family (Figure 3). Our tree also showed a paraphyletic Pouteria Aubl. The complete chloroplast genome of Mimusops coriacea may contribute to future evolutionary studies within Sapotaceae, including a better comprehension of generic limits and interspecific relationships. 


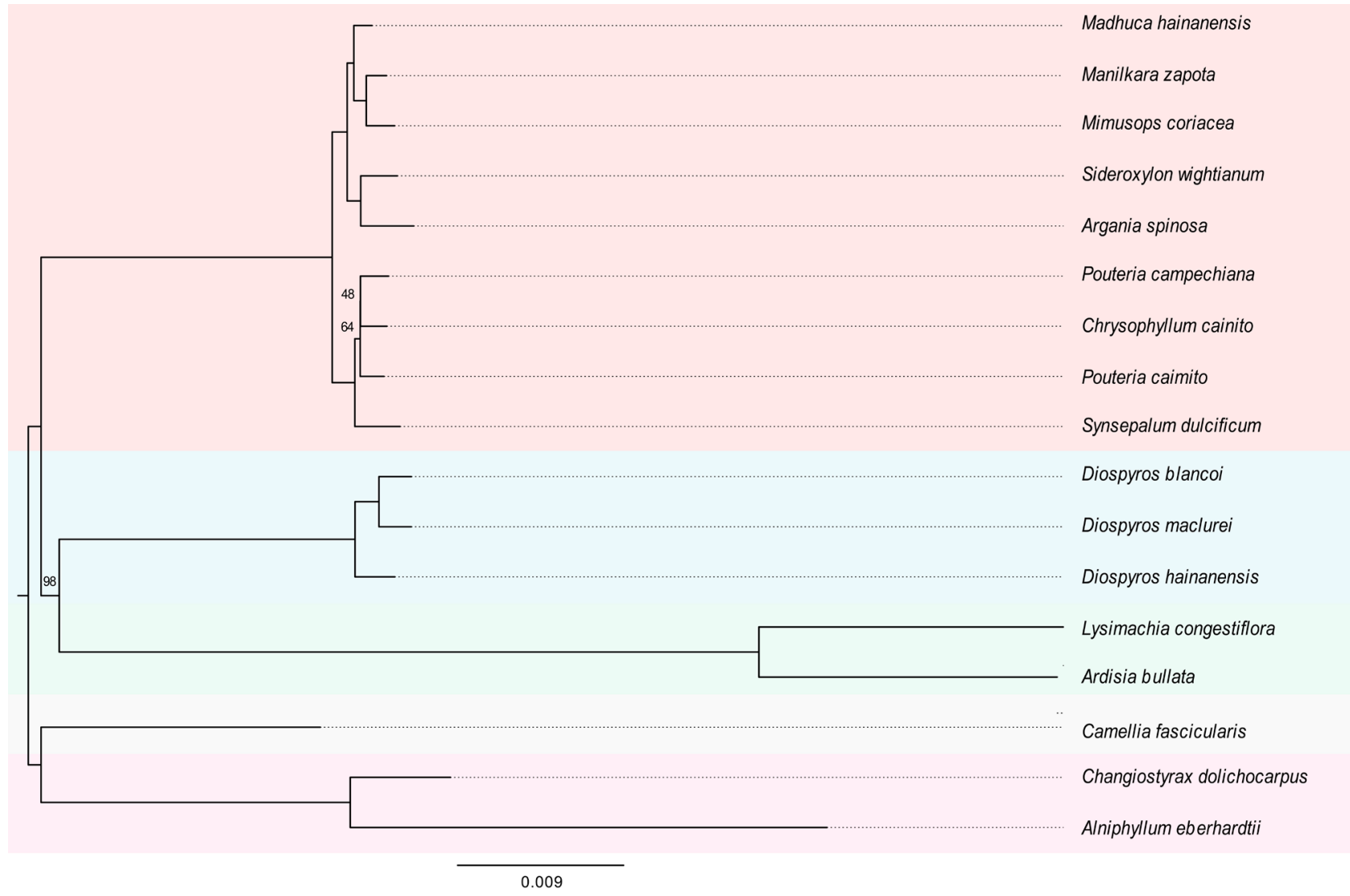

Figure 3 - Phylogenetic tree of 16 Ericales species based on 80 chloroplast protein-coding genes and four rRNAs generated by maximum likelihood method. Numbers above branches represent ultrafast bootstrap support values; nodes with support lower than $100 \%$ are indicated. Theaceae and Styracaceae were used as outgroups. The background was colored as follows: Sapotaceae - red, Ebenaceae - blue, Primulaceae - green, Theaceae - gray, Styracaceae - pink.

\section{Acknowledgements}

We would like to thank Profa. Dra. Anete P. Souza for allowing the use of CBMEG - Unicamp cluster, and Profa. Dra. Aparecida Donisete de Faria and Prof. Dr. Anderson Alves-Araújo who identified the specimen. This work was supported by Fundação de Apoio à Pesquisa do Estado de São Paulo (FAPESP) under Research Grant 2012/51781-0 to M.C.E.A. and a Postdoctoral Fellowship 2018/02285-6 to S.R.S.; Conselho Nacional de Desenvolvimento Científico e Tecnológico (CNPq) under PROTAX Grant 562299/2010-6, Universal Research Grant 482988/2013-4 and a Research Grant 311744/2017-6 to M.C.E.A., and the scholarships 142484/20148 and 205856/2014-4 to R.J.T.; FAEPEX/Unicamp Grant 1124/13 to M.C.E.A.; and Coordenação de Aperfeiçoamento de Pessoal de Nível Superior (CAPES - finance code 001) Doctoral Fellowship to R.J.T.

\section{Conflict of Interest}

The authors declare no conflict of interest.

\section{Author Contributions}

RJT designed the study and collected the data. RJT and SRS conceived and conducted the analyses. RJT, SRS and MCEA discussed the results. RJT wrote the first version of the manuscript with input from all authors. All authors read and approved the final version.

\section{References}

Alves-Araújo A, Moraes QS, Miranda VS, Nichio-Amaral R and Ribeiro M (2020) Novelties in Sapotaceae from the Espírito Santo state, Brazil: Updated checklist and new records with emended descriptions for two species. Feddes Repert 131:251-259.

Amiryousefi A, Hyvönen J and Poczai P (2018) IRscope: An online program to visualize the junction sites of chloroplast genomes. Bioinformatics 34:3030-3031.

Aubreville A (1964) Les Sapotacées: Taxonomie et phytogéographie. Adansonia 1:1-157.

Baehni C (1965) Mémoires sur les Sapotacées. 3. Inventaire des genres. Boissiera 11:1-262.

Beier S, Thiel T, Münch T, Scholz U and Mascher M (2017) MISAweb: A web server for microsatellite prediction. Bioinformatics 33:2583-2585.

Braukmann TWA, Broe MB, Stefanovic S and Freudenstein JV (2017) On the brink: The highly reduced plastomes of nonphotosynthetic Ericaceae. New Phytol 216:254-266.

Bustamante K, Santos-Ordóñez E, Miranda M, Pacheco R, Gutiérrez Y and Scull R (2019) Morphological and molecular barcode analysis of the medicinal tree Mimusops coriacea (A.DC.) Miq. collected in Ecuador. PeerJ 7:e7789.

Bustamante Pesantes KE, Gutiérrez Gaitén YI, Chóez Guaranda IA and Miranda Martinez M (2021) Composición química, capacidad antioxidante y actividad antiinflamatoria de los frutos de Mimusops coriacea (A.DC) Mig (Sapotaceae) que crece en Ecuador. J Pharm Pharmacogn Res 9:33-48.

Cai X-L, Landis JB, Wang H-X, Wang J-H, Zhu Z-X and Wang H-F (2021) Plastome structure and phylogenetic relationships of Styracaceae (Ericales). BMC Ecol Evol 21:103. 
Darling ACE, Mau B, Blattner FR and Perna NT (2004) Mauve: Multiple alignment of conserved genomic sequence with rearrangements. Genome Res 14:1394-1403.

Dierckxsens N, Mardulyn P and Smits G (2017) NOVOPlasty: De novo assembly of organelle genomes from whole genome data. Nucleic Acids Res 45:e18.

Doyle JJ and Doyle JL (1987) A rapid DNA isolation procedure from small quantities of fresh leaf tissue. Phytochemistry 19:11-15.

Gautier L, Nusbaumer L, Garratt R, Randrianaivo R and Phillipson PB (2012) Mimusops coriacea (A. DC.) Miq. (Sapotaceae): Nomenclature, distribution and ecology. Candollea 67:148-151.

Jo S, Kim HW, Kim YK, Cheon SH and Kim KJ (2016) The first complete plastome sequence from the family Sapotaceae, Pouteria campechiana (Kunth) Baehni. Mitochondrial DNA B Resour 1:734-736.

Katoh K and Standley DM (2013) MAFFT multiple sequence alignment software version 7: Improvements in performance and usability. Mol Biol Evol 30:772-780.

Kearse M, Moir R, Wilson A, Stones-Havas S, Cheung M, Sturrock S, Buxton S, Cooper A, Markowitz S, Duran C et al. (2012) Geneious Basic: An integrated and extendable desktop software platform for the organization and analysis of sequence data. Bioinformatics 28:1647-1649.

Khayi S, Gaboun F, Pirro S, Tatusova T, Mousadik AE, Ghazal H and Mentag R (2020) Complete chloroplast genome of Argania spinosa: Structural organization and phylogenetic relationships in Sapotaceae. Plants (Basel) 9:1354.

Kurtz S, Choudhuri JV, Ohlebusch E, Schleiermacher C, Stoye J and Giegerich R (2001) REPuter: The manifold applications of repeat analysis on a genomic scale. Nucleic Acids Res 29:4633-4642.

Langmead B and Salzberg S (2012) Fast gapped-read alignment with Bowtie 2. Nat Methods 9:357-359.

Larson DA, Walker JF, Vargas OM and Smith SA (2020) A consensus phylogenomic approach highlights paleopolyploid and rapid radiation in the history of Ericales. Am J Bot 107:1-17.

Laslett D and Canback B (2004) ARAGORN, a program to detect tRNA genes and tmRNA genes in nucleotide sequences. Nucleic Acids Res 32:11-16.

Liu J, Ren SN, Li K-X, Xu T, Niu Y-F and Shi C (2019) The complete chloroplast genome sequence of Manilkara zapota (Linn.) van Royen. Mitochondrial DNA B Resour 4:2127-2128.

Liu T-J, Zhang C-Y, Yan H-F, Zhang L, Ge X-J and Hao G (2016) Complete plastid genome sequence of Primula sinensis (Primulaceae): Structure comparison, sequence variation and evidence for $a c c \mathrm{D}$ transfer to nucleus. PeerJ 4: e2101.

Logacheva MD, Schelkunov MI, Shtratnikova VY, Matveeva MV and Penin AA (2016) Comparative analysis of plastid genomes of non-photosynthetic Ericaceae and their photosynthetic relatives. Sci Rep 6:30042.

Lohse M, Drechsel O, Kahlau S and Bock R (2013) OrganellarGenomeDRAW-a suite of tools for generating physical maps of plastid and mitochondrial genomes and visualizing expression data sets. Nucleic Acids Res 41:W575-W581.

Minh BQ, Schmidt HA, Chernomor O, Schrempf D, Woodhams $\mathrm{MD}$, von Haeseler A and Lanfear R (2020) IQ-TREE 2: New models and efficient methods for phylogenetic inference in the genomic era. Mol Biol Evol 37:1530-1534.

Miquel FAW (1863) Sapotae. In: von Martius CFP (ed) Flora Brasiliensis. Monachii \& Lipsiae, F. Fleischer, vol. 7B, pp 37-118.

Niu Y-F, Ni S-B, Liu Z-Y, Zheng C, Mao C-L, Shi C and Liu J (2018) The complete chloroplast genome of tropical and sub-tropical fruit tree Lucuma nervosa (Sapotaceae). Mitochondrial DNA B Resour 3:440-441.
Niu Y.-F., Ni S.-B. and Liu J (2020) Complete chloroplast genome of Synsepalum dulcificum D.: A magical plant that modifies sour flavors to sweet. Mitochondrial DNA B Resour 5:3052-3053.

Pennington TD (1990) Sapotaceae. Flora Neotropica Monograph 52:1-770

Rose JP, Kleistb TJ, Löfstrandc SD, Drewd BT, Schönenbergere J and Sytsma KJ (2018) Phylogeny, historical biogeography, and diversification of angiosperm order Ericales suggest ancient Neotropical and East Asian connections. Mol Phylogenet Evol 122:59-79.

Silva SR, Michael TP, Meer EJ, Pinheiro DG, Varani AM and Miranda VFO (2018) Comparative genomic analysis of Genlisea (corkscrew plants - Lentibulariaceae) chloroplast genomes reveals an increasing loss of the $n d h$ genes. PLoS One 13:e0190321.

Tao L, Shi ZG and Long QY (2021) Complete chloroplast genome sequence and phylogenetic analysis of a wild species of abiu fruit, Pouteria caimito (Ruiz \& Pavon.) Radlk. Mitochondrial DNA B Resour 6:138-139.

Thiel T, Michalek W, Varshney R and Graner A (2003) Exploiting EST databases for the development and characterization of gene-derived SSR-markers in barley (Hordeum vulgare L.). Theor Appl Genet 106:411-422.

Tillich M, Lehwark P, Pellizzer T, Ulbricht-Jones ES, Fischer A, Bock R and Greiner S (2017) GeSeq - versatile and accurate annotation of organelle genomes. Nucleic Acids Res 45:W6-W11.

Wang W-C, Chen S-Y and Zhang X-Z (2016) Chloroplast genome evolution in Actinidiaceae: clpP loss, heterogenous divergence and phylogenomic practice. PLoS One 11:e0162324.

Wang Y-H, Wicke S, Wang H, Jin J-J, Chen S-Y, Zhang S-D, Li D-Z and Yi T-S (2018) Plastid genome evolution in the earlydiverging legume subfamily Cercidoideae (Fabaceae). Front Plant Sci (9): 138.

Wang Y, Wang H-T, Chen YK, Yu J and Yang Y (2021) The complete chloroplast genome of Madhuca hainanensis (Sapotaceae), an endemic and endangered timber species in Hainan Island, China. Mitochondrial DNA B Resour 6:755-757.

\section{Internet Resources}

Alves-Araújo A (2020) Mimusops in Flora do Brasil 2020. Jardim Botânico do Rio de Janeiro, http://floradobrasil.jbrj.gov.br/ reflora/floradobrasil/FB75884 (acessed 26 April 2021).

Chlorobox, https://chlorobox.mpimp-golm.mpg.de/ (accessed 15 April 2021).

Stevens PF (2001) Angiosperm Phylogeny Website. Version 14 [and more or less continuously updated since]. http://www.mobot. org/MOBOT/research/APweb/.

\section{Supplementary material}

The following online material is available for this article:

Table S1 - Species names, family, and GenBank accession number for the sequences included in this study.

Table S2 - Number of simple sequence repeats (SSRs) and long repeats present in six Sapotaceae species.

Figure S1 - Comparison of the IR and single-copy regions junctions from six Sapotaceae plastomes.

Associate Editor: Rogério Margis

License information: This is an open-access article distributed under the terms of the Creative Commons Attribution License (type CC-BY), which permits unrestricted use, istribution and reproduction in any medium, provided the original article is properly cited. 